\title{
Emotional Competence and Leadership Styles of Managers in Private Universities in Uganda
}

\author{
Zahara F. Kiggundu ${ }^{1}$ \\ ${ }^{1}$ Kampala International University, Nairobi Campus [E-mail: faridahzahara@gmail.com]
}

\begin{abstract}
This short paper, a part of a wider study on the effectiveness of university managers in Uganda, reports on the emotional competence and leadership styles of managers in private universities in the country. Using data elicited from 240 respondents drawn from eight (8) private universities in the country, the paper reports a direct relationship between the emotional competence and leadership styles of the managers. However, the paper also observes, capacity building for the university managers has not paid due attention to the need to enhance the managers' emotional competence. Accordingly, the paper recommends that efforts to enhance the managers' effectiveness should endeavour to enhance their emotional competence.
\end{abstract}

Keywords: Emotional competence; Governance; Human resources development.

\section{Introduction}

Over the last three decades, private investors, religious bodies, groups of professionals and regional/ cultural organizations have set up higher education institutions. Indeed, the number of these institutions in the country has expanded phenomenally (cf. Figure 1). In the university sub-sector of the country's higher education industry, the mushrooming of privately owned universities has been met with optimism and pessimism alike. Although some authors have hailed the launching of the new private universities as contributing to the expansion of access to higher education as well as fuelling innovation in higher education delivery, critics have expressed concerns for the quality of the universities (see, for example, Kasozi, 2003). Flagship among the concerns that are being expressed about the quality of the private universities is their ability to adhere to the principles and practices of good governance. 


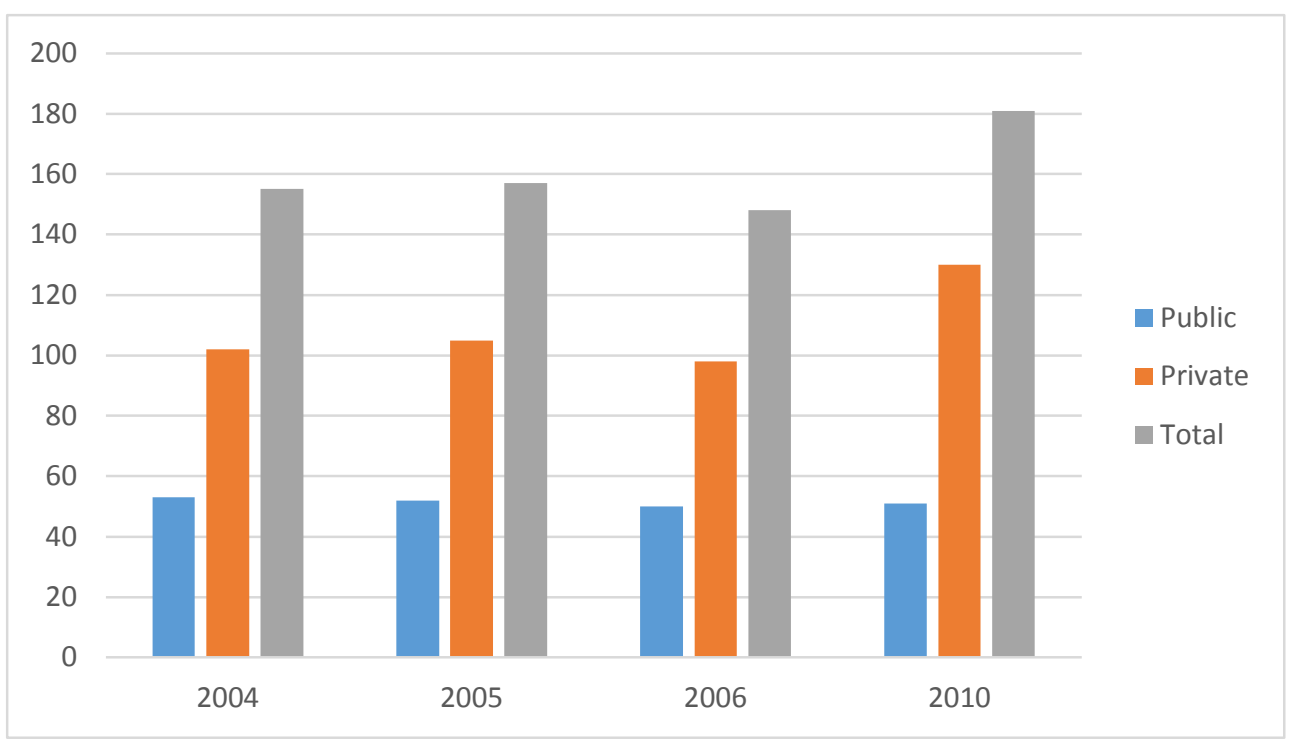

Figure 1: Ownership and Number of Higher Education Institutions in Uganda (20042010)

Source: National Council for Higher Education (2010)

According to the National Council for Higher Education (2006, p.39), "good governance in the higher education context refers to the good management of institutions of higher learning to enable them deliver quality education and to fulfil the missions and visions of all stakeholders. Universities are well governed if they fulfil the purposes for which they were established". The report adds that for universities to perform their functions, "they need to have good governance. In order to enhance good governance, university leaders must be democratic, transparent and strictly accountable to university workers, Council and to the wider general public because universities are public institutions, irrespective of the orientation, ownership, belief and ideology of their founding bodies. All decisions in universities should be made by the majority of stakeholders in relevant fora to promote the greatest happiness to the greatest number without violating the rights of the minority".

On the contrary, this ideal is not being realized in the case of many universities in Uganda. Writing on the governance of higher education in the country, for example, National Council for Higher Education (2006, p.40) reports that:

"...there were disruptions of work in some universities in 2006. For example: there were strikes by staff of Makerere University over the question of pay packages. The students joined the staff strike in sympathy; 
there was a strike in Gulu University also over the question of money matters; there were also strikes in Kyambogo University over management matters; there was a strike by students at Uganda Christian University over the issue of accommodation; an unsettled situation of conflict exists between Makerere University and its affiliate, Makerere University business School".

Clearly, these and other problems in the universities have been the result of many causes. Accordingly, resolving them requires a multifaceted approach. Regardless, a well-recognised view in efforts to deal with the problems is that resolving them effectively will depend very significantly on the leadership of the universities. The problem is that many of the leaders of the universities are ineffective, ostensibly because, as the National Council for Higher Education (2006, p.40) puts it, "Ugandan higher education managers are lifted from lecture rooms to administrative offices without training them in management". It may be noted that these gaps in university managers' competencies, as well as the resultant shortfalls in the management and operations of the universities, are particularly widespread in the private universities-congruent with the observations of authors like Altbach (2005).

In recognition of this gap in the competence of university managers, organizations like Uganda Management Institute, Inter-University Council for East Africa and Association of African Universities have designed and are offering leadership and management courses for university managers, especially those who are in the earlier part of their leadership careers. In its state of higher education in Uganda, the National Council for Higher Education also affirms its commitment to the provision of leadership and management training to leaders at various levels in the universities in the country.

However, besides the training of the university managers in management and administration, is the issue of the managers' emotional competence and its influence on the managers' leadership styles. Authors on leadership note that emotional competence is particularly central to leadership. Personal ineptitude in leaders lowers everyone's performance, wastes time, creates acrimony, corrodes motivation and commitment, and builds hostility and apathy. A leader's strengths or weakness in emotional competence can be measured in the gain or loss to the organization of the fullest talents of those they manage (Goleman, 1998). Handling emotional situations demands troubleshooting skills, being able to establish trust and rapport quickly, listening skills, and to persuade and sell a recommendation (Goleman, 1998). Accordingly, leaders require emotional competence, perspective talking, and a sense of presence, since they are responsible for the direction and control of their organization's operations. On the other hand, leadership styles are key resources for building and maintaining teams of professionals as well as for achieving change and 
reform in an effective and efficient way. Hitherto, however, a gap in knowledge that has implications for the effectiveness of the private universities in Uganda related to the fact that the link between the emotional competence and leadership styles of managers in these universities had not attracted scholarly attention. This study was undertaken to fill this gap.

\section{$2 \quad$ Related Literature}

Emotional competence, also termed as emotional self-awareness, refers to knowing one's internal states, preferences, resources and intuitions. It also involves recognizing one's emotions and their effects (Goleman, 1998). Goleman explains that although different leaders have different ways of handling situations to balance their duties, intuition may play its biggest role in work life when it comes to managing people. However, this ability lies at the heart of self-awareness. Awareness of how emotions affect what we are doing is fundamental. Thus, a leader who excels in this competence is aware of his/ her emotions at any given moment, often recognizing how those emotions feel.

Self-awareness is a cornerstone in leadership styles because it serves as an inner barometer-gauging whether what we are doing is worthwhile (Goleman, 1995). Administrators who never make a connection between how they behave under stress and their ability to retain loyalty and talent or meet the bottom-line may get an inkling that something has been missing from their leadership. This can lead to using a wrong style of management under particular circumstances due to the inner turmoil within the leader.

Accurate self-assessment accounts for knowing one's strengths and limitations. Goleman (1998) asserts that it explains why different personalities perceive and do things differently, adding that accurate self-assessment is pivotal in administration because it helps administrators to know their strengths, weaknesses, be reflective, learn from experience and open to candour, feedback and new perspectives. Salovey and Mayer et al (1995) observe that if cases of conflict at different levels of the organization are to be curbed, the administrators need to initiate or promote accurate self-assessment. These authors add that if the administrator has got poor working relationships with his or her subordinates, the imitation of accurate self-assessment among subordinates may tend to be difficult since it is hard to measure one's selfassessment which may be among the factors affecting leadership styles.

Today, we can no longer let go emotional intelligence in the management of universities. Emotional intelligence is increasingly relevant to leadership and management because it provides a new paradigm of understanding and assessing a leader's behaviour, management style, attitudes, interpersonal skills 
and potential (Khokhar \& Kush, 2009). Although universities have the right to hire the right people to fit in the right jobs, self-confidence as an element of emotional competence has to be considered vital and a sine qua non of superior performance. Without self-confidence, the administrator may lack the conviction that is essential for taking on the challenges that his/ her job presents. Self-confidence thus gives the requisite of self-assurance for moving ahead as a leader. The absence of self-confidence introduces feelings of powerlessness and crippling self-doubt. Extreme self-confidence on the other hand may look like arrogance, especially if the person lacks social skills.

Against this background, reports of management gaps in Uganda's private universities presents the universities' managers' emotional competence a candidate for investigation. The goal of such investigation is to shed light on the impact of this competence on the managers' leadership styles and, ultimately, highlight gaps and opportunities for positive intervention if any exist. It is for these reasons that this study was undertaken. And grounded on the foregoing review of related literature, the study hypothesized that there is a significant relationship between the emotional competence and leadership styles of managers in private universities in Uganda.

\section{$3 \quad$ Method}

The study was conducted following a cross-sectional survey design. Data was collected through administering two sets of questionnaires to a sample of 240 managers drawn from eight of the private universities in the country. The validity of the questionnaires was ascertained through expert judgment while their reliability was ascertained through pretesting. Analysis of variance was used to examine the variations in the levels of emotional competence and leadership styles among the categories in the sample of respondents. The relationship between attributes of the independent and dependent variables was tested using Pearson's Product Moment Correlation test at the .05 level of confidence.

\section{$4 \quad$ Findings and Discussions}

Female respondents posted a mean of 3.15 on emotional competence while their male counterparts posted a mean of 3.11. However, statistical analysis revealed that the difference is not statistically significant, a finding that corroborates Stough (2002). When considered from the view point of Goleman (1995), these findings suggest that, compared to men, women may be high in 
recognizing their feelings. This finding is corroborated by Brackett and Mayer (2003) whose study found that female participants scored higher than males on emotional intelligence when measured by a performance scale.

Regarding self-confidence, it was found that there is no significant difference in self-confidence and the leadership styles by gender. The study further indicated that there is a significant relationship between self-confidence and leadership styles $(r=.409$, sig. $=0.000)$. This implies that, if a leader has selfconfidence then the style of leadership to be used will be appropriate depending on the situation. These findings are in line with a statement that, self-confidence may provide individual administrators with greater perceived control over interpersonal events (Goleman, 1998) and that these administrators possess high levels of self-efficacy and provide orientation for followers.

A key inference here is that efforts to enhance the university managers' effectiveness should, among other things, make efforts to improve the managers' self-confidence. Conversely, review of documents like the National Council for Higher Education's state of higher education reports $(2006,2010)$ shows that attention has not been paid to this area. Although the reports highlight gaps in the management of the universities, two panaceas are primarily considered: 1) training of the managers in the areas of management; and 2) promulgation and enforcement of more stringent policies and laws that might ensure adherence to known best practices in higher education institution administration. Attention is not paid to the emotional competence of the people deployed in the management of the universities, apparently because, hitherto, evidence of a linkage between this competence and the leaders' effectiveness had not been established. However, given the findings of this study, it is recommended that in addition to the other efforts being made to enhance the capacity of university managers, efforts should be made to enhance their emotional competence. Accordingly, it is recommended that future researchers investigate into ways through which universities (and other relevant organizations like the National Council for Higher Education) may enhance the emotional competence of university managers in the country.

\section{References}

Altbach, P. G. (2005). Universities: family style. International Higher Education. Number 39, spring 2005.

Bracket, M. A., Mayer, J. D. (2003). Convergent, discriminant, and incremental validity of competing measures of emotional intelligence. Personality and Social Psychology Bulletin, 29, 1147-1158. 
Goleman, D. (1995). Emotional intelligence: why it can matter more than IQ. London: Bloomsbury Publishing.

Goleman, D. (1998). Working with Emotional Intelligence. New York: Bantam.

Kasozi, A. B. K. (2003). University education in Uganda: challenges and opportunities for reform. Kampala: Fountain Publishers.

Khokhar, C. P., Kush, T. (2009). Emotional Intelligence and Work Performance among Executives. Europe's Journal of Psychology, 5(1), 1-11.

NCHE (2006). The state of higher education and training in Uganda 2006: a report on higher education delivery and institutions. Author.

NCHE (2010). The state of higher education and training in Uganda 2010: a report on higher education delivery and institutions. Author.

Ogunyemi, A. O. (2007). Nurturing Leaders' Emotional Intelligence Through Brainstorming and Emotional Mastery Training Programmes: Implications for Human Resource Management. Paper presented at the Conference of Counselling Association of Nigeria (CASSON) held at Covenant University Otta from 14th - 17th August, 2007. Available online at: http://www.leadingtoday.org/weleadinlearning/nurturingleaders.html.

Salovey, P., Mayer, J. D., Goldman, S. L., Turvey, C., Palfai, T. P. (1995). Emotional attention, clarity, and repair: exploring emotional intelligence using the trait metamood scale. In Pennebaker, J.W. Emotion, Disclosure and Health. Washington D.C.: American Psychological Association (pp. 124154). 